\title{
Canine placenta: a source of prepartal prostaglandins during normal and antiprogestin-induced parturition
}

\author{
Mariusz Pawel Kowalewski, Hakki Bülent Beceriklisoy ${ }^{1}$, Christiane Pfarrer $^{2}$, Selim Aslan ${ }^{1}$, \\ Hans Kindahl ${ }^{3}$, Ibrahim Kücükaslan ${ }^{1}$ and Bernd Hoffmann
}

Clinic for Obstetrics, Gynecology and Andrology of Large and Small Animals, Justus-Liebig-University Giessen, 35392 Giessen, Germany, ${ }^{1}$ Clinic for Obstetrics and Gynecology, Faculty of Veterinary Medicine, University Ankara, 06110 Ankara, Turkey, ${ }^{2}$ Department of Veterinary Anatomy, Histology and Embryology, Justus-Liebig-University Giessen, 35392 Giessen, Germany and ${ }^{3}$ Division of Reproduction, Department of Clinical Sciences, SLU-Sveriges Lantbruksuniversitet, 75007 Uppsala, Sweden

Correspondence should be addressed to M P Kowalewski who is now at Vetsuisse Faculty, Institute of Veterinary Anatomy, University of Zurich, Winterthurerstrasse 260,CH-8057 Zurich, Switzerland; Email: kowalewskipl@yahoo.de, kowalewski@vetanat.uzh.ch

H B Beceriklisoy is now at Clinic for Obstetrics and Reproductive Diseases, Faculty of Veterinary Medicine, University of Adnan Menderes, 09100 Aydin, Turkey

C Pfarrer is now at Department of Anatomy, University of Veterinary Medicine, 30173 Hannover, Germany

\begin{abstract}
Expression of cyclooxygenase 2 (COX2, now known as PTGS2), prostaglandin E2 synthase (PTGES, PGES), and prostaglandin F2 $\alpha$ synthase (PGFS), of the respective receptors PTGFR (FP), PTGER2 (EP2), and PTGER4 (EP4) and of the progesterone receptor (PGR, PR) was assessed by real-time PCR, immunohistochemistry (IHC), or in situ hybridization (ISH) in utero/placental tissue samples collected from three to five bitches on days 8-12 (pre-implantation), 18-25 (post-implantation), and 35-40 (mid-gestation) of pregnancy and during the prepartal luteolysis. Additionally, ten mid-pregnant bitches were treated with the antiprogestin aglepristone $(10 \mathrm{mg} / \mathrm{kg} \mathrm{bw}(2 \times / 24 \mathrm{~h}))$; ovariohysterectomy was 24 and $72 \mathrm{~h}$ after the second treatment. Plasma progesterone and 15-ketodihydro-PGF2 $\alpha$ (PGFM) concentrations were determined by RIA. Expression of the PGR was highest before implantation and primarily located to the endometrium; expression in the placenta was restricted to the decidual cells. PTGS2 was constantly low expressed until mid-gestation; a strong upregulation occurred at prepartal luteolysis concomitant with an increase in PGFM. PGFS was upregulated after implantation and significantly elevated through early and mid-gestation. PTGES showed a gradual increase and a strong prepartal upregulation. PTGFR, PTGER2, and PTGER4 were downregulated after implantation; a gradual upregulation of PTGFR and PTGER2 occurred towards parturition. ISH and IHC co-localized PGFS, PTGFR, PTGES, and PTGS2 in the trophoblast and endometrium. The changes following application of aglepristone were in the same direction as those observed from mid-gestation to prepartal luteolysis. These data suggest that the prepartal increase of PGF2 $\alpha$ results from a strong upregulation of PTGS2 in the fetal trophoblast with the withdrawal of progesterone having a signalling function and the decidual cells playing a key role in the underlying cell-to-cell crosstalk.
\end{abstract}

Reproduction (2010) 139 655-664

\section{Introduction}

In the dog, corpora lutea $(\mathrm{CL})$ reach full functional capacity between days 20 and 30 after ovulation; thereafter, the more gradual decrease indicates luteal regression. The resulting course of progesterone $\left(\mathrm{P}_{4}\right)$ concentrations in peripheral plasma is almost identical in pregnant and nonpregnant dogs until about day 60 of luteal lifespan when the more gradual decline observed so far turns into a steep one as a precondition for parturition, which generally occurs 63 days after mating. In the nonpregnant dog, however, the gradual decline continues to levels $<1 \mathrm{ng} / \mathrm{ml}$ about 10-20 days later (Concannon et al. 1989,
Hoffmann et al. 1994). These deviating patterns in $P_{4}$ secretion may be seen as an indication for different mechanisms regulating a) gradual luteal regression in nonpregnant dogs and b) prepartal luteolysis.

Both luteotropic and luteolytic mechanisms in pregnant and nonpregnant dogs have been addressed in a number of papers. Gonadotropic support is required for luteal maintenance in pregnant and nonpregnant bitches during somewhat more than the second half of luteal lifespan with prolactin rather than $\mathrm{LH}$ being the major luteotropic factor (Okkens et al. 1990). Yet, luteal regression occurs in spite of an increased availability of prolactin (Gräf 1978) and LH (Hoffmann \& Schneider 1993). 
Recently, the role of prostaglandins in luteal regression in the nonpregnant bitch has been addressed (Hoffmann et al. 2004, Kowalewski et al. 2006a, 2008a). As hysterectomy does not interfere with normal ovarian function (Hoffmann et al. 1992), a role of CL-derived prostaglandin F2 $\alpha$ (PGF2 $\alpha$ ) acting as a luteolytic agent via para-/autocrine mechanisms was postulated, also in analogy to the situation observed in other species, i.e. cattle (Diaz et al. 2002). However, the results obtained rather support a luteotropic effect of PGE2 during the first third of luteal lifespan (Kowalewski et al. 2008b) than a luteolytic role of PGF2 $\alpha$.

The observed luteolytic response of the canine $C L$ to systemic application of PGF2 $\alpha$ agonists (Concannon \& Hansel 1977, Romagnoli et al. 1991) does not contradict this hypothesis as the $\mathrm{CL}$ rather constantly express the PGF2 $\alpha$ receptor (PTGFR) following its formation around day 15 after ovulation (Kowalewski et al. 2008a).

In pregnant bitches for the immediate prepartal release of PGF2 $\alpha$, a clear role in respect to inducing myometrial contractions could be deduced (Nohr et al. 1993, Hoffmann et al. 1999). Indications on a luteolytic role are equivocal and only relate to the observations by Hoffmann et al. (1996), who reported about a somewhat prolonged pregnancy in two dogs following application of the cyclooxygenase inhibitor indomethacin.

The situation is further hampered by the fact that there are no data on the origin of the prepartally released PGF2 $\alpha$ and the underlying mechanisms triggering this release.

Cyclooxygenase 2 (PTGS2) is the essential enzyme allowing for the formation of $\mathrm{PGH} 2$, the common precursor of PGF2 $\alpha$ and PGE2. The reduction of $\mathrm{PGH} 2$ by 9,11-endoperoxidase reductase activity of prostaglandin F2 $\alpha$ synthase (PGFS) is the major route for PGF2 $\alpha$ synthesis leading to the synthesis of PGF2 $\alpha$ directly from PGH2. However, alternatively PGF $2 \alpha$ could also be formed via 9-ketoprostaglandin reductase or 11-ketoprostaglandin reductase activity using the PGH2-derived PGE2 and PGD2 as substrates respectively (Asselin \& Fortier 2000, Madore et al. 2003).

As the canine PGFS cDNA sequence was originally cloned and described based on the mRNA isolated from utero/placental cross sections of late pregnant dogs (Kowalewski etal. 2008a), there is a distinct likelihood that the utero/placental unit could be the origin of the prepartal PGF2 $\alpha$ release. This would resemble the situation in cattle, where strongly upregulated PTGS2 levels are observed during parturition in the uninucleated trophoblast cells indicating that the fetal part of the placenta (cotyledon) may be involved in the prepartal output of PGF2 $\alpha$ and PGE2 in this species (Schuler et al. 2006).

Both prostaglandins show strong functional interrelationships; thus, PGE2 acts on softening the cervix prior to and during the uterine contractions, triggered by the action of PGF2 $\alpha$ (Stys et al. 1981, Fuchs et al. 1984). Additionally, it has been suggested that PGE2 plays an essential role in controlling the differentiation of endometrial stromal cells into decidual cells (decidualization) and hence in implantation, as has been shown in mice (Pakrasi \& Jain 2008).

Taking together the information available so far, it was hypothesized that in the dog placenta-derived prostaglandins might play a role in the prepartal preparation of the genital tract possibly also contributing to prepartal luteolysis. We therefore tested for the expression of PTGS2, PGFS, prostaglandin E2 synthase (PTGES), and the respective PGF2 $\alpha$ and PGE2 receptors (PTGFR, PTGER2, and PTGER4). As the decidual cells of maternal origin are the only cells in canine placenta expressing the progesterone receptor (PGR; Vermeirsh et al. 2000), an immediate functional interrelationship between CL-derived $\mathrm{P}_{4}$ and placental function is suggested. Therefore, also expression of the PGR was assessed as well as the concentrations of $\mathrm{P}_{4}$ and 15-ketodihydroPGF2 $\alpha$ (PGFM), the major metabolite of PGF2 $\alpha$, in peripheral plasma. In order to gain further information on the underlying mechanism, the same parameters were assessed after application of the PGR blocker aglepristone to terminate pregnancy.

\section{Results}

\section{Normal pregnancy and parturition}

\section{Progesterone and PGFM concentrations}

As was already shown for $\mathrm{P}_{4}$ (Kowalewski et al. 2009), mean progesterone concentrations were: 35.71 $\pm 7.9 \mathrm{ng} / \mathrm{ml}$ in the pre-implantation period, $29.73 \pm 13.23$ $\mathrm{ng} / \mathrm{ml}$ in the post-implantation period, $13.32 \pm 8.66$ $\mathrm{ng} / \mathrm{ml}$ at mid-gestation, and $2.07 \pm 0.99 \mathrm{ng} / \mathrm{ml}$ during the prepartal progesterone decline; the effect of time was highly significant $(P<0.0019$; Fig. $1 \mathrm{~A})$. The course of the PGFM concentrations also showed a highly significant effect of time $(P<0.0001)$ with highest values occurring during prepartal luteolysis revealing an inverse relationship in the course of $\mathrm{P}_{4}$ and PGFM
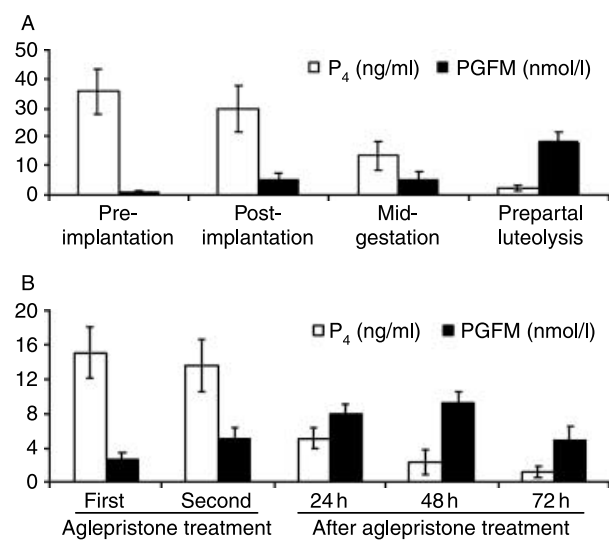

Figure 1 Progesterone $\left(\mathrm{P}_{4} ; \mathrm{ng} / \mathrm{ml}\right)$ and prostaglandin $\mathrm{F} 2 \alpha$ metabolite (PGFM; nmol/I) profiles in peripheral blood plasma of bitches during pregnancy and normal luteolysis (A) and during aglepristone-induced luteolysis (B). 
concentrations (Fig. 1A). The mean PGFM concentrations were: $0.85 \pm 0.26 \mathrm{nmol} / \mathrm{l}$ in the pre-implantation period, $4.82 \pm 2.3 \mathrm{nmol} / \mathrm{l}$ in the post-implantation period, $5.44 \pm 2.2 \mathrm{nmol} / \mathrm{l}$ at mid-gestation, and $18.2 \pm 3.67$ $\mathrm{nmol} / \mathrm{l}$ during prepartal luteolysis (Fig. 1A).

\section{Expression of PGR mRNA and immunohistochemical localization in the utero/placental unit}

Expression of mRNA revealed a highly significant effect of time $(P<0.0001)$. It was highest in the pre-implantation period (Fig. 2A) and decreased significantly $(P<0.001)$ thereafter with no further changes observed towards the end of gestation (Fig. 2A). In the pre-implantation group, immunohistochemistry (IHC) located PGR to the endometrial stroma and to nuclei of both glandular and superficial epithelial cells, as well as in the smooth muscle cells of the myometrium (Fig. 3A). Following formation of the placenta, decidual cells were the only cells of the placental labyrinth strongly expressing the PGR (Fig. 3C). No signals could be detected in the endothelial cells of maternal and fetal vessels or in the trophoblast (Fig. 3C). No or only weak signals were seen in the maternal stroma and epithelial cells of deep endometrial glands and in the superficial endometrial glands referred to as glandular chambers of the utero/ placental unit (not shown). The myometrial PGR signals remained detectable throughout pregnancy.

\section{Expression of PTGS2 mRNA and immunohistochemical localization in utero/placental unit}

Real-time RT-PCR revealed a significant $(P<0.0005)$ effect of time; expression was low until prepartal luteolysis when a highly significant $(P<0.001)$ increase in PTGS2 mRNA expression occurred (Fig. 4A). As observed by IHC, the endometrium of the pre-implantation group stained
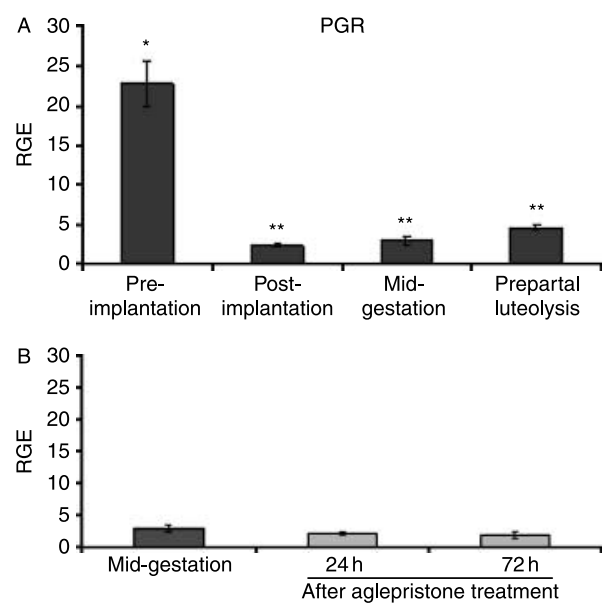

Figure 2 Expression of progesterone receptor (PGR) as determined by real-time (TaqMan) PCR during pregnancy and normal luteolysis (A) and during aglepristone-induced luteolysis (B; compared with the mid-gestation group). $R G E$, relative gene expression (mean \pm s.D.); bars with different asterisks differ with $P<0.001$. negative, while strong signals were observed in the myometrium at all stages of pregnancy (Fig. 3B).

Following formation of the placenta, a distinct staining for PTGS2 was localized to the invading trophoblast surrounding large maternal vessels at the base of the placental labyrinth; at the time of prepartal luteolysis, it had spread over the entire trophoblast (Fig. 3D). No staining was seen in the endothelial cells of maternal or fetal vessels or stromal cells. Only occasionally, some decidual cells showed a weak staining (Fig. 3D). With the beginning of implantation, some positive signals were also detected in the endometrial glands, especially in the deep endometrial glandular epithelium (not shown).

Expression of PGFS and PTGFR mRNA and localization in the utero/placental unit

Expression of $P G F S$ and $P T G F R$ mRNA showed a significant effect of time $(P<0.0008$ and $P<0.02$ respectively). Expression of PGFS mRNA was lowest during the preimplantation period, followed by an increase $(P<0.05)$ in the post-implantation and mid-gestation periods (Fig. 4C). It decreased thereafter until prior to parturition by $\sim 3.7$-fold.

Expression of PTGFR mRNA revealed a biphasic expression pattern (Fig. 4E) and was similarly high in the pre-implantation period and during prepartal luteolysis, but distinctly lower in the post-implantation $(P<0.05)$ and mid-gestation periods (Fig. 4E).

Cellular localization of PGFS and PTGFR mRNA by in situ hybridization (ISH) reflected localization of PTGS2. Virtually, all trophoblast cells stained positive during prepartal luteolysis, especially the invading trophoblast at the base of the placental labyrinth and in the area of the glandular chambers (Fig. 5A and B) where glandular epithelial cells were also positive.

Expression of PTGES, PTGER2, and PTGER4 mRNA and localization in the utero/placental unit

Expression patterns of PTGES and of the PGE2 receptors, PTGER2 and PTGER4, showed a significant effect of time $(P<0.0001, P<0.0001$, and $P<0.05$ respectively). PTGES mRNA showed the lowest expression during the pre-implantation period, a gradual increase until mid-gestation and was significantly elevated $(P<0.001)$ during prepartal luteolysis (Fig. 6A).

The biphasic expression pattern of PTGER2 (Fig. 6C) with a significant upregulation during the pre-implantation period and prepartal luteolysis $(P<0.001$ and $P<0.05$ respectively) resembled that of PTGFR (Fig. $4 \mathrm{E}$ ). Expression of PTGER4 mRNA was highest during the preimplantation period and significantly lower $(P<0.05)$ at prepartal luteolysis (Fig. 6E).

ISH located PTGES mRNA in the same cells as PGFS mRNA with strongest signals observed in the trophoblast cells (Fig. 5C). The same location was observed for the mRNA of PTGER2 and PTGER4 (not shown). 

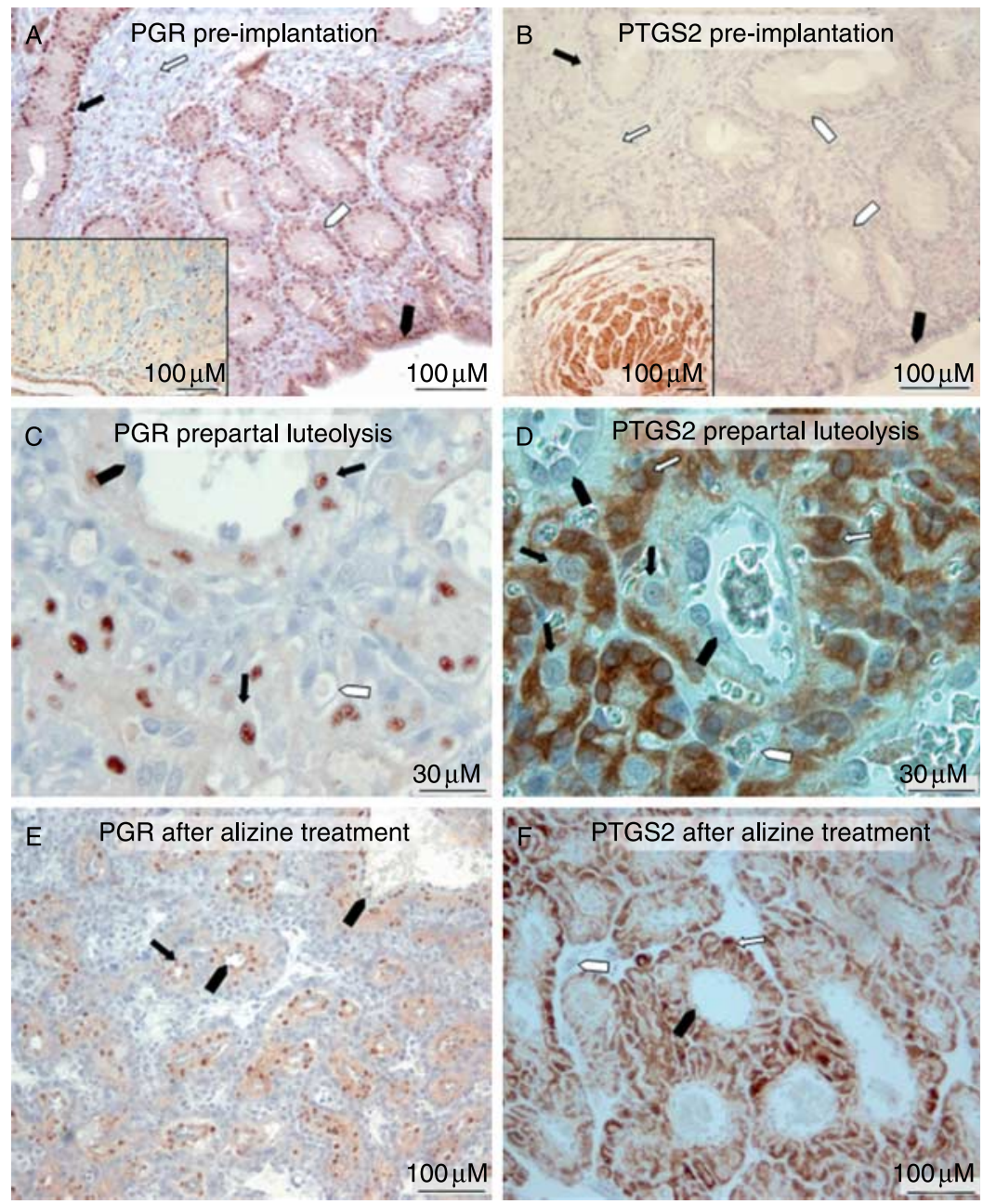

Figure 3 Immunohistochemical localization of progesterone receptor (PGR) and PTGS2 in canine endometrium at the pre-implantation stage of pregnancy ( $\mathrm{A}$ and $\mathrm{B}$ ) and in the placenta during normal and aglepristone-induced luteolysis $(\mathrm{C}-\mathrm{F})$. The insets to $A$ and $B$ show the myometrial expression of PGR and PTGS2 respectively. (A and B) Pre-implantation PGR is localized in nuclei of endometrial luminal epithelial cells $(\boldsymbol{G})$ and epithelial cells of superficial ( $\square$ ) and deep

$\Rightarrow$ ) endometrial glands; in contrast, PTGS2 is exclusively expressed in myometrium (inset to B). $\Rightarrow$, glandular covering layer (connective tissue). (C-F) In the placental labyrinth during normal and aglepristone-induced luteolysis, maternal blood vessels $(\boldsymbol{D})$ with characteristic big endothelial cells and fetal blood vessels $(\square)$ are staining negatively for PGR and PTGS2. Maternal decidual cells $(\vec{b})$ show only weak and/or sporadic PTGS2 signals, but very strong PGR immunoreactivity. Fetal trophoblast $(\triangle)$ is the only component of the placental labyrinth staining strongly for PTGS2.

\section{Induced parturition}

As parturition was induced around days 40-45, the expression of all factors assessed was compared with the mid-gestation group, which was used as a nontreated control in the statistical evaluation applying the Dunnett's multiple comparison test. For all factors, the observed changes in mRNA expression following application of the antiprogestin were in the same direction as those observed from mid-gestation to prepartal luteolysis. Thus, there was a significant upregulation of PTGS2 $(P<0.001$; Fig. 4B), PTGES $(P<0.01)$, and PTGER2 $(P<0.01$; Fig. $6 \mathrm{~B}$ and $\mathrm{D})$. The increase of PTGFR ( $P>0.05)$ was not significant; all effects were more distinct at $24 \mathrm{~h}$ than at $72 \mathrm{~h}$ after treatment (Figs 4B and $\mathrm{F}$ and $6 \mathrm{~B}$ and $\mathrm{D}$ ).

Expression of PGFS and PTGER4 was decreased $(P<0.01$ and $P<0.05$ respectively) with the effect being more pronounced at $72 \mathrm{~h}$ than at $24 \mathrm{~h}$ after treatment (Figs 4D and 6F). No changes in the PGR mRNA expression were observed (Fig. 2B).
IHC (Fig. 3E and F) and ISH localized expression of all factors assessed in the same cell types as in nonantiprogestin-treated dogs.

Similarly, changes in PGFM and $\mathrm{P}_{4}$ plasma levels showed a significant effect of time $(P<0.0047$ and $P<0.0163$ respectively). The initial concentration of PGFM increased from $2.75 \pm 0.68$ to $5.04 \pm 1.36 \mathrm{nmol} / \mathrm{l}$ at the second treatment with the antiprogestin. It was high $48 \mathrm{~h}$ later $(9.33 \pm 1.1 \mathrm{nmol} / \mathrm{l})$ and decreased by $72 \mathrm{~h} \quad(4.97 \pm 1.5 \mathrm{nmol} / \mathrm{l}) . \mathrm{P}_{4}$ decreased significantly $(P<0.01)$ from $15.11 \pm 6.7 \mathrm{ng} / \mathrm{ml}$ at the first treatment to $5.1 \pm 2.7 \mathrm{ng} / \mathrm{ml}$ and $1.2 \pm 0.6 \mathrm{ng} / \mathrm{ml} 24$ and $72 \mathrm{~h}$ respectively after the second alizine treatment (Fig. 1B).

\section{Discussion}

The data obtained clearly indicate that all major components of the prostaglandin system are expressed in the utero/placental unit of the pregnant dog. However, the quantitative data obtained by real-time RT-PCR do 

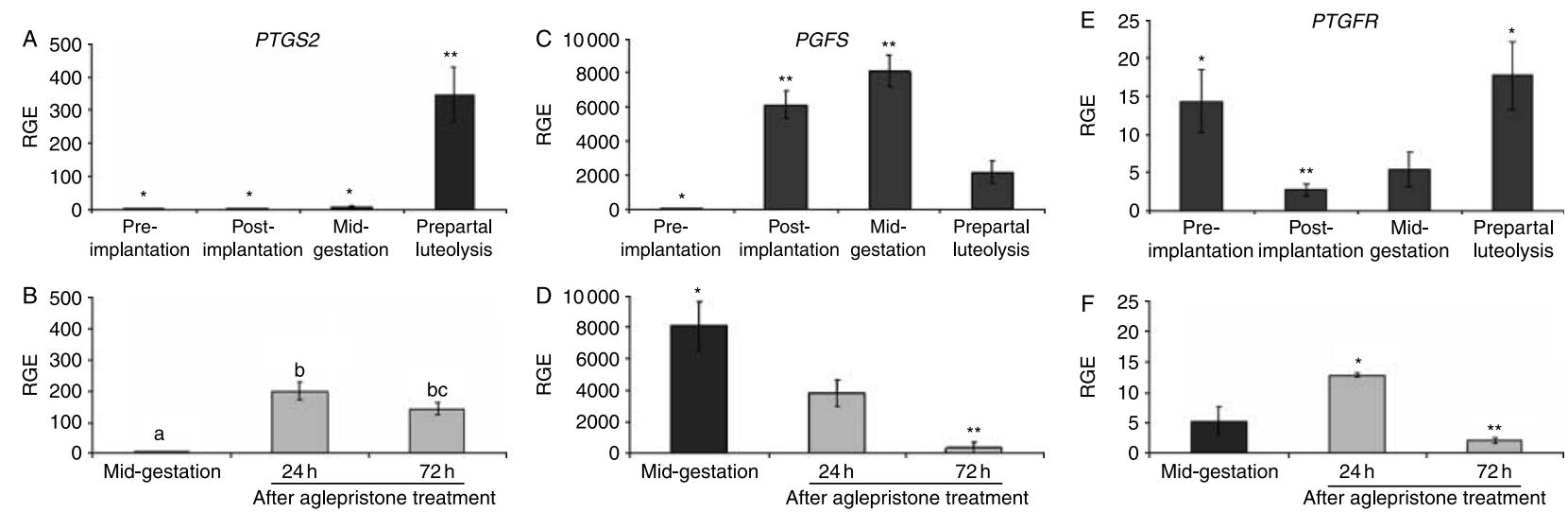

Figure 4 Expression of PTGS2, PGFS, and PTGFR as determined by real-time (TaqMan) PCR during pregnancy and normal luteolysis (A, C, and E) and during aglepristone-induced luteolysis (B, D, and F; compared with the mid-gestation group). RGE, relative gene expression (mean \pm s.D.); bars with different asterisks differ with $P<0.001$ (A) or $P<0.01$ (D), or $P<0.05$ (C, E, and F). Figure $B$, bars with different letters differ with: a versus $\mathrm{b}, P<0.001$; a versus $\mathrm{c} P<0.05$.

not allow a distinction between the uterus and/or the placenta (trophoblast) as the site of origin except for the pre-implantation period when the placenta is not yet formed. During this period, PTGS2, PGFS, and PTGES are expressed on a low level and IHC located PTGS2 solely to the myometrium. The relatively high expression of the PGF2 $\alpha$ receptor PTGFR and of the PGE2 receptors, PTGER2 and PTGER4, may be seen as signs of a high responsiveness of the uterus to PGF $2 \alpha$ and PGE2 during the pre-implantation period.

Also expression of the PGR was high during the pre-implantation period and IHC located nuclear staining predominantly to uterine epithelial cells. Thus, the responsiveness of the epithelium to $\mathrm{P}_{4}$ is maintained at least until implantation, securing the production of uterine milk (embryotrophe) and hence embryonic survival.

Following formation of the placenta, IHC localized expression of PTGS2 to the epithelial trophoblast cells; staining was initially restricted to the invading trophoblast surrounding the large maternal vessels at the base of the placental labyrinth but had spread over the entire trophoblast in the period of prepartal luteolysis, an observation accompanied by a dramatic increase in the expression of the respective mRNA and coinciding with a substantial prepartal increase of PGFM. This points towards a functional interrelationship and the role of placental PTGS2 as a rate-limiting factor in the provision of prepartal prostaglandins. Such a role of PTGS2 as a rate-limiting factor has also been observed in the horse (Boerboom et al. 2004), where blocking of endometrial PTGS2 expression by the conceptus at day 15 of early pregnancy prevented PGF $2 \alpha$-induced luteal regression allowing for continuation of pregnancy; along this line is the observation that neither PGFS nor PTGES - the essential downstream enzymes - were significantly upregulated both during the time of luteolysis in cyclic animals and during early pregnancy. Hence, an important PTGS2-related mechanism leading to the suppression of uterine luteolytic PGF2 $\alpha$ output during pregnancy in a horse has been postulated (Boerboom et al. 2004).

Based on our data and concerning the canine placenta, this increase must mainly originate in the trophoblast cells as ISH co-localized expression of PGFS to these cells. The observation that PGFS mRNA expression is higher during the post-implantation and mid-gestation periods may indicate that the expression of PGFS is regulated at the post-transcriptional level resulting in the low PGFM levels detected in peripheral plasma. On the other hand, decreased mRNA levels observed at prepartal luteolysis could be indicative for enhanced substrate turnover due to the increased PTGS2 availability during this time. However, since no corresponding data on the PGFS expression at the protein level are yet available, no final conclusion can be drawn.

Though the reduction of $\mathrm{PGH} 2$ by 9,11-endoperoxidase reductase activity is the major route for PGF2 $\alpha$ synthesis, it cannot be ruled out for sure that the formation of PGF $2 \alpha$ is through the alternative pathway via 9-ketoprostaglandin reductase or 11-ketoprostaglandin reductase activity using $\mathrm{PGH} 2$-derived PGE2 and PGD2 as substrates respectively (Asselin \& Fortier 2000, Madore et al. 2003). Such an alternative PGF2 $\alpha$ biosynthetic pathway has been identified in cattle (Madore et al. 2003) in which at least three closely related enzymes possessing the PGFS activity have been characterized within the AKR1C subclass of aldo-keto reductases family (reviewed by Madore et al. (2003)); none of them is, however, upregulated during the time of luteolysis. As reported by the same group, also another previously described enzyme 20a-hydroxysteroid dehydrogenase (AKR1B5) is capable of converting $\mathrm{PGH} 2$ into PGF2 $\alpha$ and reveals an enhanced endometrial 

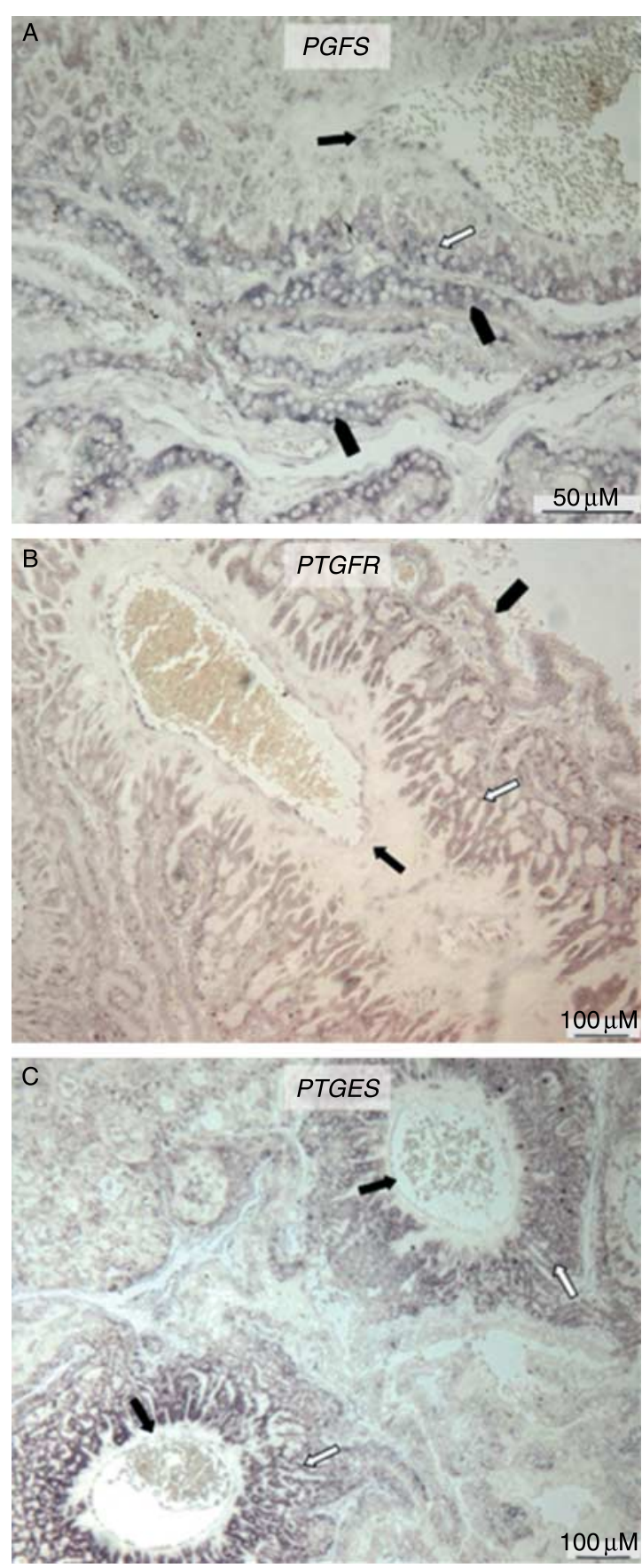

Figure 5 Localization of PGFS (A), PTGFR (B), and PTGES (C) by in situ hybridization $(\mathrm{ISH})$ in canine placenta during luteolysis. Strong mRNA signals for PGFS, PTGFR, and PTGES are observed in fetal trophoblast $(\vec{D})$, specifically that invading large maternal blood vessels $(\vec{b})$. $\mathbf{D}$, Superficial endometrial glands (glandular chambers). The same mRNA localization pattern was observed after the aglepristone treatment.

expression in cyclic cows around the time of luteolysis (Madore et al. 2003). Similarly, in the rabbit the aldoketo reductase activity is associated with both the PGE 9-reductase and 20 $\alpha$-hydroxysteroid dehydrogenase activity (Wintergalen et al. 1995).
Following these observations, further studies concerning the alternative PGF2 $\alpha$-biosynthetic pathways in canine placental compartment should be considered.

Similar to PGF2 $\alpha$, PGE2 also seems to originate from the trophoblast cells as ISH located mRNA expression of PTGES to these cells, with the expression being significantly elevated during prepartal luteolysis. As there are no data on the expression on the protein level and PGE2 plasma concentration, this observation must be interpreted very carefully and only seen as a hint that the increased availability of PTGS2 during prepartal luteolysis is associated with a basic increased capacity to release PGE2 by the placental compartment during prepartal luteolysis. Within the utero/placental unit, the trophoblast seems to be the major target for PGF2 $\alpha$ and PGE2 as ISH localized their receptors primarily to these cells.

Interestingly, both PTGFR and PTGER2 mRNA were upregulated during prepartal luteolysis, while PTGER4 mRNA was downregulated. This allows the conclusion that prepartal trophoblast function is affected by PGF $2 \alpha$ and PGE2, triggering different signalling cascades possibly in relation to the mechanisms allowing for final placental maturation and release. The expression of PGE2 receptors, EP1 and EP3, was either not detectable or only very weak in the canine corpus luteum (Kowalewski et al. 2008b) pointing towards its organ/ species-specific expression as has also been shown for the mouse CL (Segi et al. 2003). Hence, our conclusions on the role of PGE2 in regulation of canine placenta function would require further information on the expression of these receptors in the canine uterine/ placental compartment.

Taken together, our data suggest a paracrine/autocrine role of the PTGS2-derived arachidonic acid metabolites in the processes of canine decidualization and placentation. Such an autocrine/paracrine effect of PGF2 $\alpha$ has been previously proposed in bovine placentomes from early to late gestation (Arosh et al. 2004). Similarly, PGE2 has been shown to be involved in the autocrine/ paracrine regulation of decidualization in mice (Pakrasi $\&$ Jain 2008). During the later stages of pregnancy and prepartal luteolysis, they might contribute to the final maturation and release of the placenta.

In addition, the increased availability of PGE2 in the prepartal period could be utilized as a substrate for PGF2 $\alpha$ synthesis (Asselin \& Fortier 2000, Madore et al. 2003); further studies are, however, necessary to support this conclusion.

As we have recently reported (Kowalewski et al. 2009) and except for the upregulation of PTGER2 mRNA, the expression patterns of luteal STAR, HSD3B, PTGS2, PGFS, PTGES, PTGER4, and of the PGR observed during antiprogestin (aglepristone)-induced luteolysis resemble those of physiological luteal regression. Hence, the hypothesis was forwarded (Kowalewski et al. 2009) that luteal $\mathrm{P}_{4}$ acts as an autocrine/paracrine factor within a 

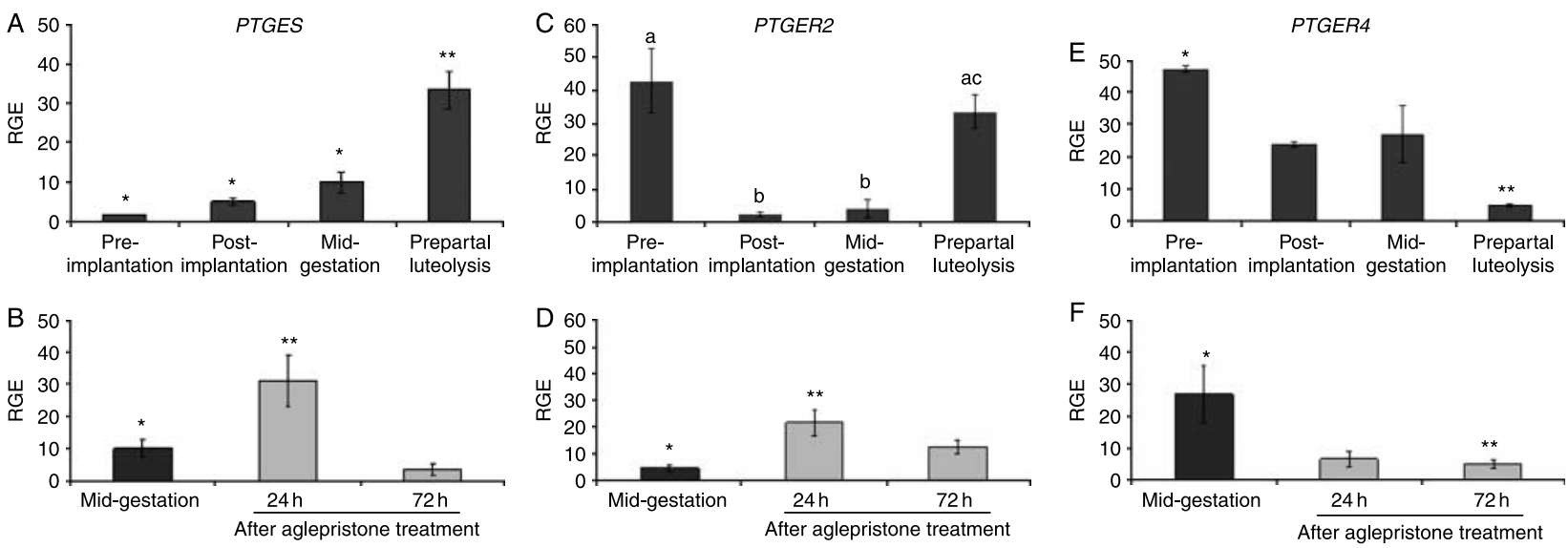

Figure 6 Expression of PTGES, PTGER2, and PTGER4 as determined by real-time (TaqMan) PCR during pregnancy and normal luteolysis (A, C, and E) and during aglepristone-induced luteolysis (B, D, and F; compared with the mid-gestation group). RGE, relative gene expression (mean \pm s.D.); bars with different asterisks differ with $P<0.001$ (A) or $P<0.01$ (B and D), or $P<0.05$ (E and F). Figure $C$, bars with different letters differ with: a versus $b$, $P<0.001 ;$ b versus $\mathrm{c}, P<0.05$.

positive loop feedback mechanism involving STAR and $\mathrm{HSD} 3 \mathrm{~B}$, and that luteal regression is not an actively controlled but rather permissive process related to aging of the $\mathrm{CL}$ as observed by electron microscopy (Hoffmann et al. 2004).

Following treatment with aglepristone on day 58 of pregnancy, Baan et al. (2008) observed an increase of PGFM parallel to a decrease of $\mathrm{P}_{4}$ levels. Our studies with aglepristone treatment between days 40 and 45 of pregnancy confirm this observation. Interestingly, also in the utero/placental unit, all changes observed concerning mRNA expression of the prostaglandin system after treatment with the antiprogestin aglepristone were in the same direction as observed during prepartal luteolysis. As the PGR is only expressed by the maternal stromaderived decidual cells as observed by Vermeirsch et al. (2000) and confirmed in this study, these cells must have an important signalling function in respect to induction of luteolysis and prepartal preparation of the utero/ placental unit for parturition.

The induction of prepartal luteolysis might then be brought upon by the fact that CL-derived $\mathrm{P}_{4}$ levels reach a critical lower threshold during the course of luteal regression affecting the crosstalk between the maternal decidual cells and the fetal trophoblast, leading to prepartal activation of the prostaglandin system as evidenced by upregulation of PTGS2 during prepartal luteolysis.

Our results also provide an explanation of the observation that aglepristone-induced parturition in the dog may require or may not require ecbolic support (Hoffmann et al. 1999, Baan et al. 2005). As provision of adequate amounts of PTGS2 seems to be restricted to the immediate phase prior to parturition, the time point of treatment with the antiprogestin seems to be the critical issue.

In summary, these observations point to an essential role of $\mathrm{P}_{4}$ not only in respect to maintenance of pregnancy by securing uterine quiescence, but also by acting as an important autocrine/paracrine and also endocrine factor in respect to luteal regression and luteolysis.

\section{Materials and Methods}

\section{Animals and tissue samples}

Animal experiments were performed in accordance with animal welfare legislation (permit no. II 25.3-19c20-15c Gl 18/14 and VIG3-19c20/15c Gl 18,14 (Gießen) and permit no. Ankara 2006/06 (Faculty of Veterinary Medicine, University of Ankara)), and all utero/placental tissue samples were obtained together with the collection of $\mathrm{CL}$ as described earlier (Kowalewski et al. 2009).

\section{Normal pregnancies}

Eighteen clinically healthy pregnant bitches of different breeds (aged 2-8 years) were divided into four groups, and utero/placental unit samples were collected via ovariohysterectomy (OHE) on one of the following days of pregnancy:

Group 1; pre-implantation, days $8-12, n=5$.

Group 2; post-implantation, days $18-25, n=5$.

Group 3; mid-gestation, days 35-40, $n=5$.

Group 4; prepartal, progesterone decline, $n=3$.

In group $4, \mathrm{P}_{4}$ concentrations were monitored every $6 \mathrm{~h}$ beginning on day 58 of pregnancy, and OHE was performed when $\mathrm{P}_{4}$ continued to decrease below $3 \mathrm{ng} / \mathrm{ml}$ in two consecutive measurements.

\section{Induced abortion}

Ten bitches were treated with the antiprogestin aglepristone between 40 and 45 days of pregnancy using the dose recommended for induction of abortion $(10 \mathrm{mg} / \mathrm{kg}$ bw, 2 times $24 \mathrm{~h}$ apart). OHE was performed $24 \mathrm{~h}(n=5)$ and $72 \mathrm{~h}(n=5)$ after the second injection. 


\section{Tissue preservation and determination of $P_{4}$ and PGFM}

Immediately after their removal, tissue samples were washed with PBS, trimmed off the surrounding connective tissue, immersed for $24 \mathrm{~h}$ in RNAlater (Ambion Biotechnologie $\mathrm{GmbH}$, Wiesbaden, Germany), and then stored at $-80^{\circ} \mathrm{C}$ until further use. For IHC and ISH, tissue samples were fixed for $24 \mathrm{~h}$ in $10 \%$ neutral phosphate-buffered formalin, washed with PBS, dehydrated in a graded ethanol series, and embedded in paraffin-equivalent Histo-Comp (Vogel, Giessen, Germany).

Established RIA procedures were used for the assay of peripheral blood plasma progesterone (Hoffmann et al. 1973) and the prostaglandin F2 $\alpha$ metabolite PGFM (Kindahl et al. 1976, Granström \& Kindahl 1982).

\section{RNA extraction, semi-quantitative real-time (TaqMan) $P C R$, and data evaluation}

Total RNA was isolated from utero/placental unit samples using TRIzol Reagent (Gibco-BRL, Life Technologies) and treated with DNase I recombinant, RNase-free, to eliminate genomic DNA contaminations (Roche Molecular Biochemicals) according to the manufacturer's instructions.

The primers were ordered from MWG Biotech AG; the 6-carboxyfluorescein (6-FAM) and 6-carboxytetra methylrhodamine (TAMRA)-labeled probes were from Eurogentec, B-4102 Seraing, Belgium. Semi-quantitative real-time PCR experiments and the comparative $C_{\mathrm{t}}$ method $\left(\Delta \Delta C_{\mathrm{t}}\right.$ method) for the relative quantification of genes were performed as previously described (Kowalewski et al. 2006a). The results are expressed as the fold change in gene expression over the calibrator.

Sequences for primers and TaqMan probes were as follows:

\begin{tabular}{|c|c|}
\hline PTGS2 (forward): & $\begin{array}{l}\text { 5'-GGA GCA TAA CAG AGT } \\
\text { GTG TGA TGT G-3'; }\end{array}$ \\
\hline PTGS2 (reverse): & $\begin{array}{l}5^{\prime} \text {-AAG TAT TAG CCT GCT } \\
\text { CGT CTG GAA T-3 }{ }^{\prime} ;\end{array}$ \\
\hline PTGS2 (TaqMan probe): & $\begin{array}{l}5^{\prime} \text {-CGC TCA TCA TCC CAT } \\
\text { TCT GGG TGC T-3'; }\end{array}$ \\
\hline PTGES (forward): & $\begin{array}{l}\text { 5'-CTG TCA TCA CCG GCC } \\
\text { AAG T-3'; }\end{array}$ \\
\hline PTGES (reverse): & $\begin{array}{l}5^{\prime} \text {-CCT GGT CAC TCC GGC } \\
\text { AAT A-3 }{ }^{\prime} ;\end{array}$ \\
\hline PTGES (TaqMan probe): & $\begin{array}{l}\text { 5'-ACG CCC TGA GAC ACG } \\
\text { GAG GCC T-3'; }\end{array}$ \\
\hline PTGER2 (forward): & $\begin{array}{l}\text { 5'-CAC CCT GCT GCT GCT } \\
\text { TCT C-3 }{ }^{\prime} ;\end{array}$ \\
\hline PTGER2 (reverse): & $\begin{array}{l}5^{\prime}-\mathrm{CGG} \text { TGC ATG CGG ATG } \\
{\text { AG- } 3^{\prime}}^{\prime}\end{array}$ \\
\hline PTGER2 (TaqMan probe): & $\begin{array}{l}\text { 5'-TGC TCG CCT GCA ACT } \\
\text { TTC AGC GTC-3'; }\end{array}$ \\
\hline PTGER4 (forward): & $\begin{array}{l}5^{\prime} \text {-AAA TCA GCA AAA ACC } \\
\text { CAG ACT TG-3'; }\end{array}$ \\
\hline PTGER4 (reverse): & 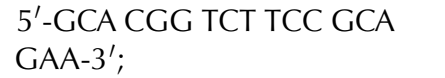 \\
\hline PTGER4 (TaqMan probe): & $\begin{array}{l}\text { 5'-ATC CGA ATT GCT GCT } \\
\text { GTG AAC CCT ATC C-3'; }\end{array}$ \\
\hline PGFS (forward): & 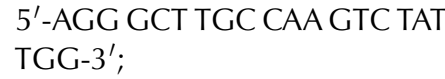 \\
\hline
\end{tabular}

\begin{tabular}{|c|c|}
\hline PGFS (reverse): & $\begin{array}{l}5^{\prime} \text {-GCC TTG GCT TGC TCA } \\
\text { GGA T- } 3^{\prime} \text {. }\end{array}$ \\
\hline PGFS (TaqMan probe): & $\begin{array}{l}5^{\prime} \text {-TCC AAC TTT AAC CGC AGG } \\
\text { CAG CTG G-3'; }\end{array}$ \\
\hline PTGFR (forward): & $\begin{array}{l}5^{\prime} \text {-ACC AGT CGA ACA TCC } \\
\text { TTT GCA-3'; }\end{array}$ \\
\hline PTGFR (reverse): & $\begin{array}{l}5^{\prime} \text {-GGC CAT CAC ACT GCC TAG } \\
\text { AAA- } 3^{\prime} ;\end{array}$ \\
\hline PTGFR (TaqMan probe): & $\begin{array}{l}5^{\prime} \text {-CAT GGT GTT CTC CGG TCT } \\
\text { GTG CCC-3'; }\end{array}$ \\
\hline$P G R$ (forward): & $\begin{array}{l}5^{\prime} \text {-CGA GTC ATT ACC TCA GAA } \\
\text { GAT TTG TTT-3'; }\end{array}$ \\
\hline$P G R$ (reverse): & $\begin{array}{l}\text { 5'-CTT CCA TTG CCC TTT TAA } \\
\text { AGA AGA-3'; }\end{array}$ \\
\hline PGR (TaqMan probe): & $\begin{array}{l}\text { 5'-AAG CAT CAG GCT GTC ATT } \\
\text { ATG GTG TCC TAA CTT-3 }{ }^{\prime} ;\end{array}$ \\
\hline GAPDH (forward): & $\begin{array}{l}5^{\prime} \text {-GCT GCC AAA TAT GAC GAC } \\
\text { ATC A-3 }{ }^{\prime} ;\end{array}$ \\
\hline GAPDH (reverse): & $\begin{array}{l}5^{\prime}-\mathrm{GTA} \text { GCC CAG GAT GCC TTT } \\
\text { GAG-3'; }\end{array}$ \\
\hline GAPDH (TaqMan probe): & $\begin{array}{l}5^{\prime} \text {-TCC CTC CGA TGC CTG CTT } \\
\text { CAC TAC CTT-3'. }\end{array}$ \\
\hline
\end{tabular}

\section{Immunohistochemical staining}

Owing to the restricted availability of canine-specific and/or cross-reacting antibodies, the immunohistochemical detection of target genes was limited to PTGS2 and the PGR.

Utero/placental cross sections were cut (4 $\mu \mathrm{m}$ thick) and mounted on SuperFrost Plus microscope slides (Menzel-Gläser; Braunschweig, Germany). The standard immunoperoxidase detection method applied was as previously described (Kowalewski et al. 2006a). The antibodies used were: monoclonal mouse anti-rat PTGS2 IgG, clone 33, BD Pharmingen (Heidelberg, Germany) and mouse mAb generated against amino acids 922-933 (C-terminal) of the human PGR, clone 10A9, Immunotech, Hamburg, Germany. An isotypespecific irrelevant mAb IgG1 (Dianova, Hamburg, Germany) was used as a negative control. The biotinylated horse antimouse IgG BA2000 was from Vector Laboratories Inc., Burlingame, CA, USA. The peroxidase activity was detected with NovaRed substrate kit according to the manufacturer's instructions (Vector Laboratories). Finally, sections were counterstained with hematoxylin and mounted with Histokit (Assistant, Osterode, Germany).

\section{In situ hybridization}

The following primers derived from canine-specific gene sequences were used in RT-PCR to generate templates for subsequent cRNA probe synthesis:

PGFS (forward): 5'-GAT CTC TGT GCC ACA TGG GAG-3'; PGFS (reverse): 5'-TGG GTC CTT CAG GAG AAC TGG-3'; PTGFR (forward): 5'-TGT GCC CAC TTT TTC TAG GC-3'; PTGFR (reverse): 5'-TCT TCC CAG TCT TTG ATG TG-3'; PTGES (forward): 5'-ACC ATC TAC CCC TTC CTG T-3'; PTGES (reverse): 5' - CTG CTT CCC AGA CGA TCT -3'; 
PTGER2 (forward): 5'-TTC TCC TGG CTA TTA TGA CC-3'; PTGER2 (reverse): 5'-ATC TAC TGG CGT TTG ACT G-3'; PTGER4 (forward): 5'-GGT ACG GGT GTT CAT CAA C-3'; PTGER4 (reverse): 5'-AGA GGA GGG TCT GAG ATG TG-3'.

The length of the amplicons was: 235, 291, 214, 273, and 323 bp for PGFS, PTGFR, PTGES, PTGER2, and PTGER4 respectively.

The further procedure was as previously described (Kowalewski et al. 2006b). Briefly, the PCR products were cloned into the pGEM-T plasmid (Promega). Digestion of the harvested pGEM-T plasmid clones containing the respective inserts was by using the restriction enzymes Ncol (antisense cRNA) and Not (sense cRNA; New England Biolabs, Frankfurt, Germany). The synthesis of digoxigenin (DIG)-labeled cRNA was achieved with DIG RNA labeling kit from Roche Molecular Biochemicals. Semi-quantitation of the DIG-labeled cRNA was by dot blot analysis of serial dilutions of cRNA probes on a positively charged Nylon Membrane (Roche Molecular Biochemicals). Paraffin-embedded utero/placental cross sections were mounted on the SuperFrost Plus slides (Menzel Glaeser, Braunschweig, Germany), dewaxed, digested with $70 \mu \mathrm{g} / \mathrm{ml}$ proteinase $\mathrm{K}$ (Sigma-Aldrich Chemie $\mathrm{GmbH}$ ), and postfixed with $4 \%$ paraformaldehyde and then processed according to the procedure by Lewis \& Wells (1992) and Klonisch et al. (1999). Detection of the DIG-labeled cRNA probes was by alkaline phosphatase-conjugated sheep anti-DIG Fab fragments (Roche Molecular Biochemicals) diluted 1:5000 in 1\% ovine serum followed by incubation with the substrate 5-bromo-4-chloro-3-indolyl phosphate in the presence of nitroblue tetrazolium (Roche Molecular Biochemicals).

\section{Statistical analysis}

To test for an effect of time in the respective group, a parametric one-way ANOVA was applied. Multiple comparison post-tests were performed in case of $P<0.05$. Those were Tukey-Kramer multiple comparison test in experiments measuring the expression of target genes during the course of pregnancy and Dunnett's multiple comparison test in experiments showing the expression of genes after aglepristone-induced luteolysis. In the latter, the results present the fold change in gene expression compared to its expression at mid-gestation. Owing to the uneven distribution of the real-time data obtained for the PTGS2, PGFS, and PTGER4, data were analyzed using the Kruskal-Wallis test (a nonparametric ANOVA) followed by Dunn's multiple comparison test. Numerical data were presented as the mean \pm s.D. For all tests, the statistical software program, GraphPad 3.06 (GraphPad Software, Inc., San Diego, CA, USA) was used.

\section{Declaration of interest}

The authors declare that there is no conflict of interest that could be perceived as prejudicing the impartiality of the research reported.

\section{Funding}

This study was funded with support of the German Research Foundation. The authors also greatly appreciate the support of Virbac, Germany, in providing the aglepristone and financial support of the aglepristone associated studies.

\section{References}

Arosh JA, Banu SK, Chapdelaine P \& Fortier MA 2004 Temporal and tissue specific expression of prostaglandin receptors EP2, EP3, EP4, FP, and cyclooxygenases 1 and 2 in uterus and fetal membranes during bovine pregnancy. Endocrinology 145 407-417.

Asselin E \& Fortier MA 2000 Detection and regulation of the messenger for a putative bovine endometrial 9-keto-prostaglandin E2 reductase: effect of oxytocin and interferon-tau. Biology of Reproduction 62 125-131.

Baan M, Taverne MAM, Kooistra HS, de Gier J, Dieleman SJ \& Okkens AC 2005 Induction of parturition in the bitch with the progesterone-receptor blocker aglépristone. Theriogenology 63 1958-1972.

Baan M, Taverne MAM, de Gier J, Kooistra HS, Kindahl H, Dieleman SJ \& Okkens AC 2008 Hormonal changes in spontaneous and aglepristoneinduced parturition in dogs. Theriogenology 69 399-407.

Boerboom D, Brown KA, Vaillancourt D, Poitras P, Goff AK, Watanabe K, Doré M \& Sirois J 2004 Expression of key prostaglandin synthases in equine endometrium during late diestrus and early pregnancy. Biology of Reproduction 70 391-399.

Concannon PW \& Hansel W 1977 Prostaglandin F2 $\alpha$ induced luteolysis, hypothermia and abortion in beagle bitches. Prostaglandins 13 533-542.

Concannon PW, McCann JP \& Temple M 1989 Biology and endocrinology of ovulation, pregnancy and parturition in the dog. Journal of Reproduction and Fertility Supplement 39 3-25.

Diaz FJ, Anderson LE, Wu YL, Rabot A, Tsai SJ \& Wiltbank MC 2002 Regulation of progesterone and prostaglandin F2 $\alpha$ production in the $\mathrm{CL}$. Molecular and Cellular Endocrinology 191 65-80.

Fuchs AR, Goeschen K, Rasmussen AB \& Rehnstrim JV 1984 Cervical ripening by endocervical and extra-amniotic PGE2. Prostaglandins $\mathbf{2 8}$ 217-227.

Gräf KJ 1978 Serum oestrogen and prolactin concentrations in cyclic, pregnant and lactating beagle dogs. Journal of Reproduction and Fertility 52 9-14.

Granström E \& Kindahl H 1982 Radioimmunoassay of the major plasma metabolite of PGF2a, 15-keto-13,14-dihydro-PGF2a. Methods in Enzymology 86 306-320.

Hoffmann B \& Schneider S 1993 Secretion and release of luteinizing hormone during the luteal phase of the oestrus cycle in the dog. Journal of Reproduction and Fertility Supplement 47 85-91.

Hoffmann B, Kyrein HJ \& Ender ML 1973 An efficient procedure for the determination of progesterone by radioimmunoassay applied to bovine peripheral plasma. Hormone Research 4 302-310.

Hoffmann B, Höveler R, Hasan SH \& Failing K 1992 Ovarian and pituitary function in the dog following hysterectomy. Journal of Reproduction and Fertility 96 837-845.

Hoffmann B, Höveler R, Nohr B \& Hasan SH 1994 Investigations on hormonal changes around parturition in the dog and the occurrence of pregnancy-specific non conjugated oestrogens. Experimental and Clinical Endocrinology 102 185-189.

Hoffmann B, Riesenbeck A \& Klein R 1996 Reproductive endocrinology of bitches. Animal Reproduction Science 42 257-288.

Hoffmann B, Riesenbeck A, Schams D \& Steinetz BG 1999 Aspects on hormonal control of normal and induced parturition in the dog. Reproduction in Domestic Animals 34 219-226.

Hoffmann B, Büsges F, Engel E, Kowalewski MP \& Papa P 2004 Regulation of corpus luteum-function in the bitch. Reproduction in Domestic Animals 39 232-240.

Kindahl H, Edqvist LE, Granström E \& Bane A 1976 The release of prostaglandin F2a as reflected by 15-keto-13,14-dihydroprostaglandin F2a in the peripheral circulation during normal luteolysis in heifers. Prostaglandins 11 871-878. 
Klonisch T, Hombach-Klonisch S, Froehlich C, Kauffold J, Steger K, Steinetz BG \& Fischer B 1999 Canine preprorelaxin: nucleic acid sequence and localization within the canine placenta. Biology of Reproduction 60 551-557.

Kowalewski MP, Schuler G, Taubert A, Engel E \& Hoffmann B 2006a Expression of cyclooxygenase 1 and 2 in the canine corpus luteum during diestrus. Theriogenology 66 1430-1432.

Kowalewski MP, Mason JI, Howie AF, Morley SD, Schuler G \& Hoffmann B $2006 b$ Characterization of the canine $3 \beta$-hydroxysteroid dehydrogenase and its expression in the corpus luteum during diestrus. Journal of Steroid Biochemistry and Molecular Biology 101 254-262.

Kowalewski MP, Mutembei HM \& Hoffmann B 2008a Canine prostaglandin F2a receptor (FP) and prostaglandin F2a synthase (PGFS): molecular cloning and expression in the corpus luteum. Animal Reproduction Science 107 161-175.

Kowalewski MP, Mutembei HM \& Hoffmann B 2008b Canine prostaglandin E2 synthase (PGES) and its receptors (EP2 and EP4): expression in the corpus luteum during dioestrus. Animal Reproduction Science 109 319-329.

Kowalewski MP, Beceriklisoy HB, Aslan S, Agaoglu AR \& Hoffmann B 2009 Time related changes in luteal prostaglandin synthesis and steroidogenic capacity during pregnancy, normal and antiprogestin induced luteolysis in the bitch. Animal Reproduction Science $\mathbf{1 1 6}$ 129-138.

Lewis FA \& Wells M 1992 Detection of virus in infected human tissue by in situ hybridization. In In Situ Hybridization - A Practical Approach, pp 121-135. Ed. DG Wilkinson. Oxford: Oxford University Press.

Madore E, Harvey N, Parent J, Chapdelaine P, Arosh JA \& Fortier MA 2003 An aldose reductase with $20 \alpha$-hydroxysteroid dehydrogenase activity is most likely the enzyme responsible for the production of prostaglandin F2 $\alpha$ in the bovine endometrium. Journal of Biological Chemistry 278 11205-11212.

Nohr B, Hoffmann B \& Steinetz BE 1993 Investigation of the endocrine control of parturition in the dog by application of an antigestagen. Journal of Reproduction and Fertility Supplement 47 542-543.
Okkens AC, Bevers MM, Dieleman SJ \& Willemse AH 1990 Evidence for prolactin as the main luteotrophic factor in the cycling dog. Veterinary Quarterly 12 193-201.

Pakrasi PL \& Jain AK 2008 Cyclooxygenase-2 derived PGE2 and PGI2 play an important role via EP2 and PPARdelta receptors in early steps of oil induced decidualization in mice. Placenta 29 523-530.

Romagnoli SE, Cela M \& Camillo F 1991 Use of prostaglandin F2 $\alpha$ for early pregnancy termination in the mismated bitch. Veterinary Clinics of North America. Small Animal Practice 21 487-499.

Schuler G, Teichmann U, Kowalewski MP, Hoffmann B, Madore E, Fortier MA \& Klisch K 2006 Expression of cyclooxygenase-II (COX II) and 20a-hydroxysteroid dehydrogenase (20a-HSD)/prostaglandin F-synthase (PGFS) in bovine placentomes: implications for the initiation of parturition in cattle. Placenta 27 1022-1029.

Segi E, Haraguchi K, Sugimoto Y, Tsuji M, Tsunekawa H, Tamba S, Tsuboi K, Tanaka S \& Ichikawa A 2003 Expression of messenger RNA for prostaglandin E receptor subtypes EP4/EP2 and cyclooxygenase isozymes in mouse periovulatory follicles and oviducts during superovulation. Biology of Reproduction 68 804-811.

Stys SJ, Dresser BL, Ott TE \& Clark KE 1981 Effects of prostaglandin E2 on cervical compliance in pregnant ewes. American Journal of Obstetrics and Gynecology 140 415-419.

Vermeirsch H, Simoens P \& Lauwers H 2000 Immunohistochemical detection of the estrogen receptor- $\alpha$ and progesterone receptor in the canine pregnant uterus and placental labyrinth. Anatomical Record $26042-50$.

Wintergalen N, Thole HH, Galla HJ \& Schlegel W 1995 Prostaglandin-E2 9-reductase from corpus luteum of pseudopregnant rabbit is a member of the aldo-keto reductase superfamily featuring $20 \alpha$-hydroxysteroid dehydrogenase activity. European Journal of Biochemistry 234 264-270.

Received 14 April 2009

First decision 2 June 2009

Revised manuscript received 10 November 2009

Accepted 24 November 2009 